\title{
LA RACIALIZACIÓN DE LOS MEXICANOS EN ESTADOS UNIDOS: ESTRATIFICACIÓN RACIAL EN LA TEORÍA Y EN LA PRÁCTICA*
}

DOUGLAS S. MASSEY

RESUMEN: Los mecanismos de estratificación social requieren la definición categórica de un grupo externo que pueda ser excluido y explotado. Históricamente, en Estados Unidos los afroamericanos han sido sujetos a un proceso sistemático de formación racial para definirlos como parte de un grupo explotable y susceptible de exclusión. Comenzando en los años setenta y acelerándose en los ochenta y noventa, los mexicanos han sido objeto de procesos similares de exclusión para hacerlos más explotables y aptos para su exclusión que nunca antes. Como consecuencia, en la última década los mexicoamericanos se alejaron de su posición intermedia en la jerarquía económica y se acercaron a la formación de una clase inferior. Este artículo describe los mecanismos básicos de estratificación en Estados Unidos y cómo los mexicanos han sido constantemente racializados y como grupo externo deshumanizado y vulnerable.

ABSTRACT: Mechanisms of social stratification require the categorical definition of an outgroup to that can be excluded and exploited. Historically in the United States African Americans have been the subject of a systematic process of racial formation to define them as a exploitable and excludable out-group. Beginning in the 1970s and accelerating in the 1980s and 1990s, Mexicans increasingly have been subject to a similar process of racialization to render them more exploitable and excludable than ever before. As a result, over the past decade Mexican Americans moved steadily away from their middle position in the economic hierarchy and toward the formation of an underclass. This paper describes the basic mechanisms of stratification in the United States and how Mexicans have steadily been racialized as a dehumanized and vulnerable out-group.

Nota Del editor: Traducción del inglés de Luis Rodolfo Morán Quiroz.

* Office of Population Research, Princeton University. 
a estratificación social se da porque todas las sociedades humanas se caracterizan por una estructura social que divide a la gente en categorías con base en una combinación de rasgos logrados y recibidos. Las características logradas son aquellas adquiridas en el curso de la vida, mientras que las recibidas se establecen en el nacimiento. La estratificación es la distribución desigual de las personas en categorías que se caracterizan por un acceso diferencial a recursos escasos. Los recursos pueden ser materiales, como el ingreso y la riqueza; pueden ser simbólicos, como el prestigio y la posición social; o pueden ser emocionales como el amor, el afecto y el sexo. Los sistemas de estratificación ordenan verticalmente a las personas dentro de una estructura social en donde se caracteriza claramente su cima y su fondo. Aunque la cifra y el rango de las categorías sociales han aumentado dramáticamente en años recientes, los medios básicos por los cuales las personas reciben menor o mayor acceso a los recursos materiales, emocionales y simbólicos escasos ha permanecido notablemente similar a través del tiempo.

Dadas las categorías socialmente definidas y las personas distribuidas en ellas, la inequidad se genera y perpetúa a través de dos mecanismos básicos: la explotación y el acopio de oportunidades (Tilly 1998). La explotación se da cuando las personas en un grupo social expropian un recurso producido por los miembros de otro grupo social y evitan que sean concientes del valor pleno de su esfuerzo al producirlo. El acopio de oportunidades ocurre cuando un grupo social restringe el acceso a un recurso escaso, sea a través de una negativa franca o por el ejercicio de un control monopólico que requiere que los miembros de fuera de ese grupo paguen una cuota a cambio del acceso. En cualquiera de estas dos formas, el acopio de oportunidades se instaura por medio de un proceso de exclusión socialmente definido.

Ambos mecanismos son sociales por su origen y se dan como consecuencia de la búsqueda de motivos sociales centrales que resultan comunes a todos los seres humanos (Fiske 2003). En una manera bastante real, la estratificación comienza psicológicamente con la creación de fronteras cognoscitivas que asignan a las personas a categorías sociales. Antes de que la inequidad categorial pueda ser puesta en marcha socialmente, las categorías deben ser creadas en el nivel cognoscitivo para clasificar mentalmente a las personas con base en alguna combinación de características logradas y adscritas. Esta categorización de las personas sigue su propia lógica.

\section{LA ESTRATIFICACIÓN RACIAL EN TEORÍA}

Las raíces de la estratificación social descansan en última instancia en la construcción de límites para realizar distinciones sociales, una tarea que llega con naturalidad a los seres humanos, quienes están mentalmente programados para realizar 
pensamiento de clasificación (Fiske 2003). Construimos categorías generales sobre el mundo en el que vivimos y luego las usamos para clasificar y evaluar los estímulos que encontramos. Estas categorías conceptuales son conocidas colectivamente como esquemas. Representan estructuras cognoscitivas que sirven para interconectar un conjunto de estímulos, sus diversos atributos y las relaciones entre ellos (Fiske 2003).

Las personas utilizan esquemas para evaluarse a sí mismos y a los roles sociales, los grupos sociales, los eventos sociales y los actores sociales con los que se encuentran, proceso que se conoce como cognición social (Fiske 2003). Las categorías en las que dividen al mundo pueden cambiar con el tiempo y evolucionar con la experiencia, pero siempre existen entre los seres humanos maduros y pueden volver a ellas cuando interpretan objetos, eventos, personas y situaciones (Fiske 2003). Los seres humanos están psicológicamente programados para clasificar a la gente con la que se encuentran y utilizar estas categorizaciones para realizar juicios sociales.

Los esquemas sociales, empero, no existen simplemente como representaciones mentales neutrales. El cerebro humano está compuesto de dos procesadores paralelos que, aun cuando están interconectados, funcionan independientemente (Panksepp 1998; Konner 2002). El cerebro emocional tiene sus raíces en un conjunto de estructuras neurológicas comunes a todos los mamíferos y en conjunto son conocidas como sistema límbico, mientras que el cerebro racional se centra en el neocórtex, en especial el córtex prefrontral, el más desarrollado en los humanos (Damasio 1999). Las dos porciones del cerebro están neurológicamente interconectadas, pero la cantidad y la velocidad de las conexiones que van del sistema límbico al neocortex es mayor que en el sentido inverso, de modo que las memorias emotivas que se guardan en el sistema límbico, típicamente inconcientes, afectan en gran medida a la manera en que los seres humanos utilizan las categorías existentes en el cerebro racional y conciente (LeDoux 1996; Zajonc 1998).

Las emociones almacenadas en el sistema límbico pueden ser positivas o negativas pero cuando se asocian con clases particulares de personas u objetos contribuyen al prejuicio, el que constituye una orientación emotiva predeterminada ha los individuos o los objetos (Fiske 2003). Una orientación prejuiciada a favor o en contra de algún grupo social encierra componentes concientes e inconcientes (Bargh 1996). Todos los seres humanos, sea que piensen en sí mismos como prejuiciados o no, manejan esquemas mentales con los que clasifican a la gente en categorías con base en la edad, el género, la raza y la etnia (Taylor et al., 1978; Stangor et al., 1992). No pueden evitarlo. Es parte de la condición humana; y estos esquemas por lo general incluyen memorias implícitas que resultan en disposiciones inconcientes hacia las personas y los objetos, derivando en estereotipos (Fiske 1998). Las nociones estereotípicas siempre están presentes, pero las personas tienen una mayor probabilidad de caer en ellas al hacer juicios cuando se sienten 
confrontadas o enfrentan alguna amenaza o incertidumbre (Bodenhausen y Wyer 1985; Bodenhausen y Lichtenstein 1987).

Al hacer juicios sociales acerca de otros, los seres humanos parecen evaluar a las personas siguiendo dos dimensiones psicológicas: calidez y competencia (Fiske et al. 2002). La calidez refiere a qué tanto puede gustarse de una persona y a la vez qué tanto permite que se le aproximen. Nos sentimos atraídos a personas que vemos como altas en la dimensión de calidez y buscamos interactuar y pasar tiempo con ellas. Encontramos a personas que son bajas en la dimensión de calidez como personas que no nos reciben adecuadamente y por lo general las evitamos para minimizar la cantidad y el rango de contactos sociales; no gustamos de ellas y las encontramos "frías". Además, de estos sentimientos subjetivos de atracción y gusto, evaluamos a la gente también en términos de competencia y eficacia -su capacidad de actuar de manera que reflejen seguir un propósito para lograr que las cosas se hagan. Puede ser que nos guste o no la gente que es altamente competente, pero por lo general los respetamos y apreciamos su habilidad de hacer que las cosas se hagan de manera efectiva.

Estas dos dimensiones de la percepción social se unen en el modelo del contenido del estereotipo, que argumenta que la cognición social humana implica la ubicación cognoscitiva de grupos e individuos en un espacio social bidimensional definido por la intersección de ejes independientes de calidez y competencia (Fiske et al., 2002). Como se muestra en la figura 1, el espacio social para la formación de estereotipos tiene cuatro cuadrantes básicos. El cuadrante superior derecho contiene a las personas dentro del propio grupo, junto con los miembros de los grupos que percibimos como similares al propio. Naturalmente pensamos que los miembros de nuestro propio grupo son cálidos y competentes y, por tanto, son accesibles y dignos de respeto. La emoción relevante que se asocia con la percepción del propio grupo (in-group) es el orgullo.

La intersección de dos dimensiones deriva en tres distintos tipos de grupos externos (out-groups), sin embargo, los que varían en términos de su grado de acercamiento (approachability) y respecto. El cuadrante inferior derecho contiene a aquellos grupos que son vistos socialmente como competentes pero no cálidos. Se les respeta pero no se gusta de ellos y la emoción relevante que las personas sienten hacia ellos es la envidia. Este cuadrante incluye a las clásicas minorías del hombre promedio como los judíos en la Europa medieval, los chinos en Malasia, los tutti en Rwanda y los hindúes en África oriental. En una estructura social estable, las personas muestran respeto y deferencia públicos ante los miembros de los grupos externos envidiados, pero si el orden social de quebranta pueden convertirse en blanco del odio y la violencia comunitarias, incluso de genocidio, porque no se gusta de ellos ni se perciben que sean personas "como nosotros".

El cuadrante superior izquierdo incluye a los grupos externos que se ven como cálidos y por tanto dignos de que nos gusten pero que no se ven como competen- 
FIGURA 1

Representación gráfica del modelo de contenido de los estereotipos.

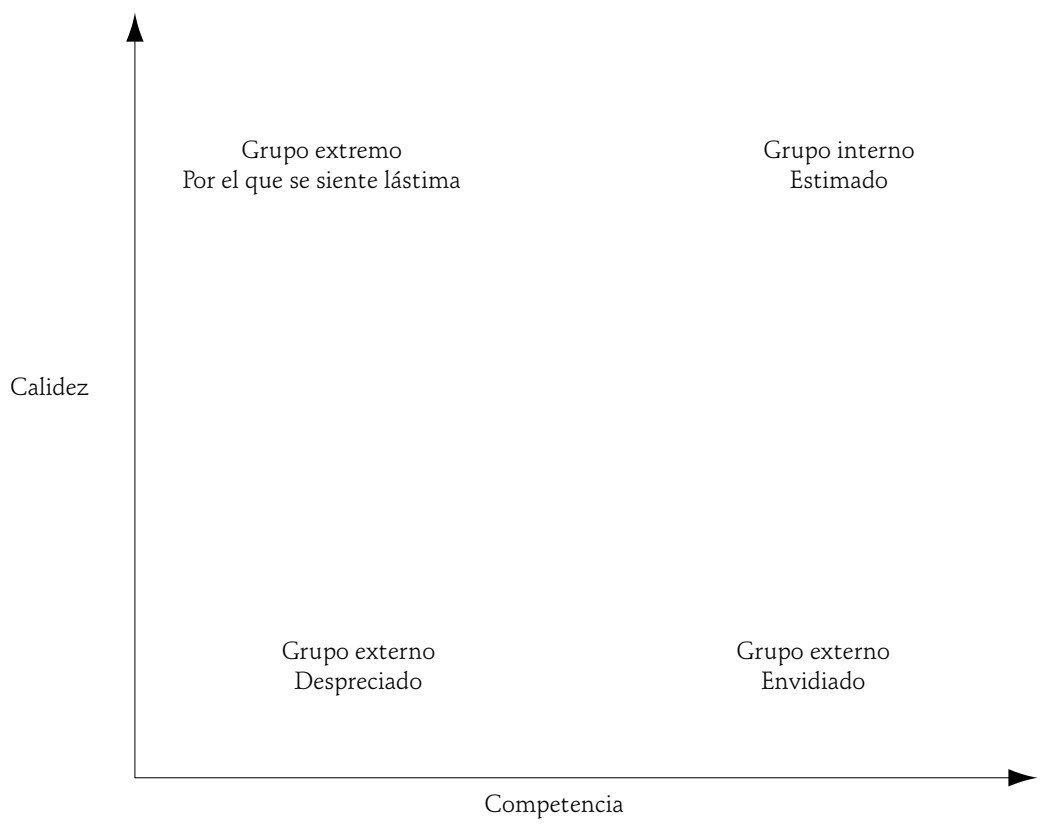

tes. Quienes caen en esta categoría son las personas que han experimentado alguna desgracia pero que sin ella serían vistos como "personas como yo", como los discapacitados, los viejos, los ciegos, los retrasados mentales. Uno puede imaginarse en sus zapatos pero por algún accidente del destino, y la emoción relevante es lástima. Nos gustan pero, al reconocer su falta de competencia también sentimos lástima por ellos y no los respetamos. En una estructura social estable los miembros de los grupos externos por los que sentimos lástima tienden a ser cuidados y atendidos; pero en épocas de desorden social pueden sufrir de abandono (como se vio en los días siguientes del huracán Katrina en Nueva Orleáns), aunque por lo general no se convierten en blanco de odio intencional o de violencia comunitaria.

Finalmente, los grupos sociales que ocupan el cuadrante inferior izquierdo son percibidos simultáneamente como bajos en calidez y bajos en competencia. Como no son dignos de gustarnos ni son capaces, las personas dentro de estos grupos externos son socialmente despreciadas y la emoción dominante es disgusto o desprecio. Este cuadrante contiene a los excluidos sociales como los traficantes de droga, los que engañan a los sistemas de beneficencia pública, los delincuentes sexuales, los desamparados y los vagabundos. También incluye a los miembros de grupos que han sido sujetos a un proceso ideológico de formación de grupo y formación de límites que cuestiona su humanidad. Los afroamericanos en el sur de Jim Crow eran percibidos por los blancos como personas que no eran competentes ni cálidas. Eran socialmente etiquetados como inferiores, incluso 
infrahumanos; y debido a que se les percibía como menos que humanos plenos, se les podía explotar, segregar, humillar y matar sin remordimiento.

El trabajo reciente en neurociencia ha involucrado una región específica del cerebro como zona central para el proceso de cognición social (véase Harris y Fiske 2006). Cada vez que los individuos perciben un estimulo como humano y por tanto como un actor social potencial, un área del cerebro conocida como el cortex medial prefrontral se ilumina cuando se le observa bajo un aparato de imágenes resonancia magnética funcional (fMRI, por sus siglas en inglés). Harris y Fiske (2006) pusieron primero a prueba una serie de fotografías de actores sociales para establecer el cuadrante en el que se les ubicaba; luego mostraban estas imágenes a sujetos experimentales de modo tal que cada persona veía un total de 80 imágenes - 20 de miembros del mismo grupo, 20 de grupos a los que se envidia, 20 de grupos por los que se siente lástima y 20 de grupos que se desprecian.

A medida que veían las diversas imágenes sociales, los cerebros de los sujetos fueron escaneados con fMrI y se registraron los centros de actividad. Como se esperaba, los investigadores encontraron que las imágenes que representaban al propio grupo, a los grupos externos envidiados y por los que se siente lástima, desataron claras reacciones en el cortex medial prefrontral. Para su sorpresa, sin embargo, las imágenes de los grupos despreciados no lo hicieron así (Harris y Fiske 2006). Mientras que los grupos externos que despertaban sentimientos de lástima y envidia eran percibidos instantáneamente como seres humanos y actores sociales, aquellos que se despreciaba no eran vistos en términos sociales en absoluto - en el nivel de cognición más fundamental. Los grupos despreciados por tanto se deshumanizaban en el nivel neuronal, dando licencia a los humanos, en sus propias mentes, para tratarlos como si fueran animales u objetos.

Este rasgo básico de la cognición social humana aporta los fundamentos psicológicos para la explotación y el acopio de oportunidades en el mundo real. La posición de un grupo dentro del espacio social definido por la calidez y la competencia no está fijo, sino que es maleable, varía según el tiempo, el espacio y la cultura (Leslie, Constantine, y Fiske 2006). Aunque las categorías sociales son construidas y mantenidas en última instancia por los individuos en el interior de sus mentes, el proceso por el cual se expresan los límites es social en última instancia. Las identidades y los límites de grupo se negocian por medio de repetidas interacciones que establecen las definiciones operativas de las categorías en cuestión, incluidas tanto el contenido subjetivo como el objetivo, un proceso que los sociólogos han etiquetado como trabajo de límites (véase Gieryn 1983; Lamont y Molnar 2002). Cuando los actores sociales logran establecer los límites y el contenido de varias categorías sociales en las mentes de los demás, los psicólogos se refieren a este proceso como enmarcado (framing) (Kahneman y Tversky 2000). En esencia, el trabajo de límites implica definir categorías en la estructura social y el enmarcado implica definirlos en la cognición humana. 
Las personas favorecen naturalmente a los límites y los enmarcados que les dan un mayor acceso a recursos materiales, simbólicos y emocionales y buscan convencer a los demás de que acepten su versión preferida de la realidad social (véase Lakoff 2002; Lakoff y Johnson 2003). En general, los actores sociales que controlan más recursos en la sociedad -los que se ubican más cerca de la cima del sistema de estratificación - tienen los mayores privilegios en cuanto al trabajo de enmarcado y trazo de límites. Históricamente, los blancos han perpetuado los estereotipos negativos de los afroamericanos como tontos, violentos, hipersexuales y tercos; y la gente rica de la misma forma ha promovido una visión de los pobres como holgazanes, carentes de motivación, indisciplinados y poco merecedores. Según sea el grado al cual estos estereotipos se convierten en parte de la cognición social cotidiana, los individuos que son miembros del grupo externo estereotipado tenderán a experimentar discriminación y exclusión en la sociedad.

Por supuesto que las distinciones sociales excluyentes y los enmarcados despreciativos siempre son cuestionados por las personas en el lado que es objeto de esas distinciones (Barth 1969). Quienes están sujetos a la explotación de un enmarcado particular de la realidad social luchan para oponérsele y substituirlo por un enmarcado alternativo más adecuado a sus intereses. De la misma forma, cuando se topan con límites categóricos que evitan que accedan a un recurso deseado, las personas trabajan activamente para resistir y subvertir las definiciones sociales de la mejor manera a su alcance. Los miembros de los grupos subyugados tienen sus propias expectativas acerca de cómo deben ser percibidos y tratados e incluso si en lo exterior se adaptan a las preconcepciones sociales de los más poderosos, por lo general trabajan en el interior para minar el orden conceptual y social dominante de maneras pequeñas y grandes.

A través de esas interacciones en dos sentidos, por más asimétricas que sean, la gente en ambos lados de una división social estratificada participa activamente en la construcción de los límites y las identidades que definen un sistema de estratificación. Sin importar cuál sea su posición en el sistema, las personas buscan definir para sí mismas el contenido y el significado de las categorías sociales, adoptando algunos elementos que les son adscritos por la sociedad dominante y rechazando otros, simultáneamente aceptando y resistiendo las limitaciones y las oportunidades asociadas con su particular status social. A través de las interacciones cotidianas con las personas y las instituciones, la gente construye una concepción de las líneas entre grupos sociales específicos (Barth 1981).

\section{LA ESTRATIFICACIÓN RACIAL EN LA PRÁCTICA HISTÓRICA}

A lo largo de la historia de Estados Unidos, muchos grupos se han convertido en objetos de prejuicio y discriminación (Perlmutter 1999; Jacobson1999). Oleadas sucesivas de inmigrantes europeos y sus descendientes han luchado duramente y 
por mucho tiempo para ser aceptados como "blancos" dentro de la sociedad estadounidense y la completa "blancura" no se logró socialmente por parte de la mayor parte de los europeos del sur y el este de ese continente sino hasta los años setenta (Alba 1990). Aunque en la actualidad existe escaso enmarcado o trazo de límites para crear distinciones sociales de importancia entre los grupos de origen europeo, la erosión de los límites entre categorías es mucho menos cierta para el grupo que en la actualidad es la minoría de más rápido crecimiento: los mexicanos.

Por sí mismos los mexicoamericanos constituyen el segundo grupo minoritario en cuanto a tamaño de la nación, con cerca de 28 millones de personas, en comparación con 38 millones de afroamericanos, y cuando se combinan con otros grupos de origen latinoamericano constituyen la minoría de mayor tamaño del país: los latinos. Los mexicanos no sólo constituyen dos terceras partes de toda la población latina; sino que también es dudoso que el angloamericano promedio pueda distinguir entre los mestizos de origen mexicano, guatemalteco, salvadoreño, peruano o colombiano. El grado al cual el trabajo de trazo de límites y enmarcado se realizan en la sociedad estadounidense para ubicar a los mexicanos como un "otro" racializado, determina que haya efectos de difusión hacia otros latinos.

Los mexicanos se introdujeron por primera vez a Estados Unidos en 1848, cuando el Tratado de Guadalupe Hidalgo puso fin a la guerra México-estadounidense y cedió a Estados Unidos los actuales estados de Texas, Arizona, Nuevo México y California, además de algunas porciones de UTA, Colorado y Nevada. Con la firma de este tratado, más de 50,000 mexicanos se convirtieron súbitamente en ciudadanos estadounidenses (Jaffe et al., 1980), y con el trazo de una pluma pasaron a ser, de mayoría en su propio país a una minoría en una tierra ajena (MacLachlan y Beezley 2003).

La mayoría de los nuevos ciudadanos vivía en Nuevo México y Texas y en este último, dado que era un estado esclavista, pronto se relegó a los mexicanos al lado inadecuado de la línea de color -no fueron esclavizados como los afroamericanos, pero ciertamente no se les concedieron los derechos y privilegios de los europeos blancos (Gutiérrez 1995). A través de una diversidad de mecanismos categoriales -algunos legales y otros no tan legales- los mexicanos fueron sistemáticamente despojados de sus propiedades y libertades y de les convirtió en jornaleros sin tierra al servicios de los propietarios y empresarios blancos (Zamora 1993; De Leon 1999). Aunque los mexicanos también fueron despojados fuera de Texas, el grado de subyugación en otros lugares no fue tan severo en sus inicios, pero poco a poco se tornó peor a medida que crecían los núcleos de población mexicana (Gutierrez 1995).

Para fines del siglo XIx, los mexicanos se habían transformado, tanto social como económicamente en un estrato subordinado que estaba sujeto a una discriminación difundida y a una exclusión sistemática (Grebler, Moore y Guzmán 1970). El grado al cual los mexicanos se habían transmutado de amos de sus propios dominios en fuente racializada de mano de obra barata para los blancos se 
muestra en el reporte de la la comisión estatal Dillinghan de 1911, en donde se describe a los mexicanos como "notablemente indolentes y poco progresistas en todo lo que se refiere a educación y cultura", realizando trabajos sucios dignos tan sólo del "grado más bajo de las razas nativas no asimilables" aunque su "utilidad, no obstante, se ve impedida en mucho por [su] falta de ambición y [su] inclinación al uso constante de licor intoxicante" (U.S. Commission on Immigration 1911: 59, 94, 110).

Los cerca de 50,000 mexicanos que fueron absorbidos hacia Estados Unidos en 1848 se incrementaron principalmente por crecimiento natural hasta el siglo XX. Aun cuando las tasas de fecundidad eran altas, también lo eran las tasas de mortalidad y la tasa de expansión demográfica era modesta. Para 1900 la población de origen mexicano en Estados Unidos alcanzaba apenas cerca de 150,000 y ese año únicamente llagaron 237 mexicanos como inmigrantes. Aun cuando el racismo contra los mexicanos era real y corriente, su pequeña cifra y su aislamiento geográfico significó que los mecanismos categóricos de inequidad establecidos para asegurar su status subordinado tuvieron escaso efecto en la inequidad dentro de la nación en conjunto.

Esta situación se alteró en 1907. Ese año, Estados Unidos y Japón cerraron un "acuerdo de caballeros" por el cual las autoridades japonesas aceptaban evitar la salida de sus ciudadanos con rumbo a Estados Unidos, a cambio de lo cual Estados Unidos acordó no infligir a Japón la indignidad de prohibir su entrada (Zolberg 2006). Esta acción causó una seria alteración en los mercados de trabajo occidentales, ya que los inmigrantes japoneses habían llegado a convertirse en la columna vertebral de la mano de obra no calificada de la región. En respuesta, los patrones occidentales miraron hacia el sur y comenzaron a reclutar mexicanos, primero para trabajar en los ferrocarriles, luego en las minas y finalmente en las fábricas (Cardoso 1980; Durand y Arias 2000).

Como lo expresó la comisión Dillinham, "la inmigración mexicana puede incrementarse por algún tiempo ya que esta raza ofrece una fuente de mano de obra para sustituir a la asiática en las ocupaciones temporales más indeseables". En efecto, continuaba la comisión, "en los dos distritos del sur de California en donde la fuerza de los jornaleros es predominantemente mexicana, se prefiere a los mexicanos sobre los japoneses. Se le considera más tratable y ser mejor trabajador en un caso. En el otro se dice que es más rápido y mejor trabajador que el japonés..." (U.S. Commission on Immigration 1911: 50, 110). Pocos mexicanos entraron a Estados Unidos antes de ese acuerdo de caballeros con Japón; pero a partir de entonces el flujo de los inmigrantes legales se aceleró rápidamente desde cerca de cero en 1907 hasta alcanzar los 16,000 en 1909.

Con el inicio de la Primera Guerra Mundial en 1914, los patrones estadounidenses se vieron privados de la mano de obra inmigrante procedente de Europa y de Asia, y a medida que creció la demanda de productos estadounidenses los 
patrones incrementaron su reclutamiento de trabajadores provenientes del sur de la frontera (Cardoso 1980). Cuando Estados Unidos entró a la Primera Guerra Mundial en 1917, al demanda de mano de obra alcanzó su cima y la escasez de trabajadores se convirtió en crónica cuando los trabajadores blancos de las fábricas se movilizaron al servicio militar. En respuesta, el gobierno estadounidense estableció un programa oficial de reclutamiento de mano de obra para apoyar a los productores agrícolas en el suroeste (Reisler 1979; Morales 1982) y los propietarios de fábricas en el medio oeste redoblaron sus esfuerzos privados de reclutamiento (Durand y Arias 2000).

De tal manera, la cifra de trabajadores bajo contrato que entraron a Estados Unidos se incrementó desde 17,000 en 1920 y la inmigración legal alcanzó una cifra sin precedente de 51,000 personas. Las incertidumbres estadounidenses acerca de todo lo extranjero se dispararon durante la recesión que siguió a la Guerra, y el Terror Rojo (Red Scare) de 1918-1921 estuvo acompañado de una ola de histeria anti-inmigrante. El congreso aprobó la primer ley de cuotas en 1921 para limitar la inmigración proveniente de Europa del sur y del este y aprobó una versión aun más estricta en 1924. Durante este periodo, tanto la inmigración legal como aquella por contrato entre los mexicanos se desplomó, alcanzando las bajas cuotas, en 1922, de 18,000 y de 12,000 en 1924.

La recuperación económica, sin embargo, llevó a una sostenida explosión económica conocida como "los fabulosos veintes" y, dadas las nuevas restricciones a la inmigración de europeos y al ajuste constante de los mercados de mano de obra, pronto se reinició el reclutamiento de mexicanos. La inmigración legal se elevó nuevamente para alcanzar la cifra de 88,000 personas en 1924 y el ingreso de jornaleros por contrato alcanzó los 18,000. Hasta ese momento, la frontera entre México y Estados Unidos era poco más que una línea en el mapa y en buena parte no estaba siquiera marcada (Massey, Durand, Malone 2002). Como respuesta a la creciente inmigración proveniente de México, empero, en 1924 el congreso creó la Patrulla Fronteriza (U.S. Border Patrol) y por primera vez la frontera entre México y Estados Unidos se convirtió en una realidad tangible.

La creación de la patrulla fronteriza significó la existencia de una nueva categoría de mexicanos en Estados Unidos -el migrante ilegal. Durante el primer año de operación la patrulla fronteriza aprehendió a cerca de 4,600 mexicanos que intentaban entrar al país sin documentos (Massey, Durand y Malone 2002). No obstante, los ingresos legales se incrementaron a mediados de la década, para llegar a los 68,000 migrantes con documentos y a 17,000 trabajadores por contrato en 1927. Al reducirse estos dos flujos a fines de los años veinte, se incrementó correspondientemente la inmigración ilegal, llegando las aprehensiones a 18,000 personas en 1930.

A partir del acuerdo de caballeros de 1907 hasta 1930, la cifra de personas de origen mexicano en Estados Unidos rebasó el cuádruplo, elevándose de 178,000 a 
739,000 en poco más de dos décadas y convirtiendo a los mexicanos en una minoría visible en las ciudades de las regiones del suroeste, el medio oeste y el Pacífico (Durand y Arias 2000). Con la caída del mercado valores estadounidense, sin embargo, el incremento en la inmigración de mexicanos se acabó tan rápido como había comenzado. Siguiendo los preceptos establecidos por la comisión Dillingham, los mexicanos se consideraron dispensables como trabajadores e incapaces de asimilar como ciudadanos y, en una época de creciente austeridad, los blancos los enmarcaron como personas que despojaban de los empleos a quienes les pertenecían, los "verdaderos" estadounidenses, generando cargas en los contribuyentes con pagos de indemnización que recompensaban su "indolencia" natural (Hoffman 1974). De acuerdo con estas percepciones, las autoridades federales se unieron con los funcionarios estatales y locales para organizar una serie de campañas de deportación, mismas que, en el curso de unos cuantos años, redujeron a la mitad la población de origen mexicano en Estados Unidos (Jaffe et al., 1980).

Durante el periodo 1929-1937, unos 458,000 mexicanos fueron arrestados y expulsados de Estados Unidos sin el proceso legal adecuado, incluidos muchos hijos de nacidos en Estados Unidos. Para 1940, solo quedaban 377,000 inmigrantes mexicanos en el país (Jaffe et al. 1980). Quienes permanecieron en él fueron empujados hacia los márgenes de la sociedad, segregados en barrios ruinosos, en donde se les atendía en escuelas segregadas y en donde recibían servicios de calidad inferior (Grebler, Moore y Guzmán 1970). En estos enclaves, los mexicanos se transformaron de aspirante a inmigrar en una minoría nacional conciente de sí, que gradualmente dejó de llamarse a sí misma "mexicana" para utilizar el término de "chicana" (Sánchez 1995; Gutiérrez 1995). El grado al cual los mexicanos fueron racializados durante este periodo se manifiesta en el hecho de que la oficina del censo de Estados Unidos en 1930, por primera y única vez en su historia enumerara a los mexicanos como una raza por sí misma, junto a los negros (Bean y Tienda 1987).

Con la entrada de Estados Unidos en la Segunda Guerra Mundial, sin embargo, la industria estadounidense una vez más se movilizó y se restableció el pleno empleo. En combinación con el reclutamiento militar renovado, la guerra generó escasez de mano de obra, en especial en el suroeste estadounidense y las autoridades federales pronto se olvidaron de las deportaciones y, sin hacer escándalo, voltearon hacia el sur para negociar un tratado binacional para la importación "temporal" de jornaleros provenientes de México, a los que se conoció como braceros. El consiguiente "Programa Bracero" estuvo operado por los Departamentos de Estado, del Trabajo y de Justicia de Estados Unidos, en cooperación con el gobierno mexicano y en septiembre de 1942 llegaron los primeros braceros para hacerse cargo del trabajo agrícola en Stockton, California (Calavita 1992).

El Programa Bracero fue instrumental para reiniciar un flujo migratorio que había estado latente por más de una década. En los años previos a 1942, la inmigración de mexicanos hacia Estados Unidos era virtualmente nula; y aunque los 
flujos se reavivaron con el Programa Bracero, la cifra de trabajadores por contrato permaneció bastante pequeña a lo largo de la guerra. Entre 1942 y 1945, un total de tan sólo 168,000 braceros se reclutaron hacia Estados Unidos. En las áreas urbanas, los hijos de los inmigrantes mexicanos de épocas anteriores aprovecharon el retorno al pleno empleo y lograron una movilidad económica ascendente, trabajando en empleos sindicalizados en las industrias de guerra y traduciendo su recién encontrada afluencia en un nuevo y llamativo estilo conocido como "pachuco", cuyo emblema era el traje holgado conocido como zoot suit (Mazon 1984).

Como sucediera en relación con los japoneses en años anteriores del siglo, los californianos blancos se resintieron de los inferiores de raza que se elevaban por encima del lugar que se les había asignado y en la cargada atmósfera de Los Ángeles en la época de la guerra se iniciaron los disturbios en contra de los mexicanos. El 3 de junio de 1943, un grupo de soldados de licencia se quejó de que habían sido atacados por una pandilla de pachuchos que llevaban zoot suits (Obregon Pagan 2006). En respuesta, una airada multitud de soldados y civiles blancos se dirigió al barrio mexicano del este de Los Ángeles, en donde sus miembros atacaron a todos los hombres que portaran zoot suits, los golpearon salvajemente al tiempo que los despojaban de los trajes ofensivos y los quemaban en el lugar.

En vez de proteger a los ciudadanos estadounidenses de origen mexicano, la policía de Los Ángeles arrasó el barrio y arrestó a cientos de pachuchos que ya habían sido golpeados, acusándolos de "alterar la paz" y varios de ellos murieron en la cárcel por falta de tratamiento médico. Aun cuando nueve marineros blancos fueron arrestados en los siguientes días, ocho de ellos fueron liberados sin cargos y al último se le liberó tras pagar una pequeña multa. Los ataques a los mexicanos cesaron únicamente cuando las autoridades militares declararon a la ciudad de Los Ángeles como un lugar prohibido para el personal en servicio. A los mexicoamericanos, empero, se les había hecho llegar un fuerte mensaje: incluso en la progresista California las personas de origen mexicano no eran aceptadas como iguales, sin importar en dónde hubieran nacido, cuánto percibieran de sueldo, o qué tan elegantes se vistieran (Mazon 1984).

Aun cuando al principio se pensó que la medida era "temporal" por el tiempo de Guerra, la vigorosa economía de la posguerra perpetuaría los temores de los agricultures de escasez de mano de obra y, bajo presión de las delegaciones del congreso provenientes de Texas y California, Casa de Representantes y el Senado ampliaron el Programa Bracero cada año hasta fines de los años cuarenta. A pesar de las ampliaciones, no obstante, la cifra de visas para braceros fue insuficiente para cubrir la creciente demanda de los agricultores y de ese modo los patrones se hicieron cargo de la situación reclutando directamente a migrantes ilegales, en especial después de 1950, cuando la restauración del reclutamiento militar forzoso durante la guerra de Corea estrechó notoriamente los mercados de mano de obra de Estados Unidos. A medida que los mexicanos cruzaban la frontera en números mayores en su viaje hacia las granjas y campos en donde sabían que 
serían contratados, la cifra anual de aprehensiones se disparó de cerca de 7,000 en 1942 hasta alcanzar los 544,000 en 1952.

Al final de la guerra de Corea, una breve recesión económica, se combinó con otro aumento en la histeria xenófoba durante la época de McCarthy para volver a la migración ilegal un tema político candente. En 1953-1954, el servicio estadounidense de inmigración y naturalización (U.S. Immigration and Naturalization Service-INS) respondió al creciente clamor lanzando la "operación espaldas mojadas" (Operation Wetback) (Calavita 1992). En cooperación con las autoridades estatales y locales, el ins militarizó la frontera entre México y Estados Unidos y organizó el arresto masivo de mexicanos -o, más exactamente, de personas que lucieran como mexicanos. Durante 1954 la cifra de mexicanos aprehendidos por el INs se disparó a más de un millón por primera vez en la historia de Estados Unidos.

Una diferencia crucial en comparación con la campaña de deportación de los años treinta, sin embargo, fue que esta vez el congreso actuó simultáneamente para ampliar la cifra de visas de trabajo temporal, duplicando casi el número de braceros admitidos por año. Entre 1955 y 1959, entre 400,000 y 450,000 braceros se importaron cada año hacia Estados Unidos. La inmigración legal se elevó también, yendo de 9,600 en 1952 a 65,000 en 1956 antes de estabilizarse (Massey, Durand y Malone 2002). Este incremento en las alternativas de ingreso legales, más que la vigilancia fronteriza reforzada, fue lo que redujo la migración ilegal a un mínimo durante los años cincuenta. De estar en una cifra de 1.1 millones en 1954, el número de aprehensiones se redujo a tan sólo 30,000 en 1959, nivel en el que permaneció ya bien entrados los años sesenta.

Durante un tiempo los estadounidenses parecían contentos de poseer fuerza de trabajo desechable que cada temporada viajaba a Estados Unidos para realizar trabajos difíciles y exigentes pero que regularmente regresaba a México una vez que se efectuaba el trabajo. Al inicio de la Operación Espalda Mojada y la expansión del Programa Bracero, la inmigración ilegal desapareció como tema político; pero a medida que tomaba fuerza el movimiento de los derechos civiles, la inmigración se volvió controvertida de manera distinta. Además de acabar con las regulaciones de Jim Crow en contra de los negros y prohibir la discriminación en los mercados estadounidenses, los activistas de los derechos civiles buscaron purgar el sistema nacional de inmigración de su legado racista. Como consecuencia, durante los años sesenta, tanto el Programa Bracero como las cuotas por origen nacional se convirtieron en blancos de ataques.

El Programa Bracero era visto por los defensores de los derechos civiles como un sistema de mano de obra corrupto, coercitivo y explotador, en buena parte a la par de las cosechas compartidas por los negros en el sur. Bajo intensa presión de grupos religiosos, sindicatos y organizaciones de derechos civiles, el congreso redujo el Programa Bracero a principios de los años sesenta -reduciendo el número de visas de trabajo por año de 438,000 en 1959 a 178,000 en 1964- antes de 
votar al año siguiente a favor de dar por terminado ese programa por completo. En el mismo año de 1965, el congreso aceptó enmiendas al Decreto de Inmigración y Nacionalización en donde finalmente se abolió la discriminación por orígenes nacionales y se levantó la prohibición en contra de la inmigración proveniente de Asia y África.

En vez de cuotas racistas, la nueva legislación estableció un límite neutral de 20,000 visas de inmigrante al año para cada uno de los países fuera del hemisferio occidental. Estas visas se distribuían entre las personas utilizando un "sistema de preferencia" que tomaba en cuenta las necesidades de empleo y humanitarias nacionales (Zolberg 2006). Aunque se le veía como un logro destacable de parte del movimiento de los derechos civiles, el Decreto de Inmigración de 1965 inauguró también una nueva tendencia en las políticas restrictivas de inmigración en el caso de México al imponer los primeros límites numéricos a la inmigración proveniente del hemisferio occidental. Las enmiendas sucesivas pusieron a cada nación del hemisferio occidental bajo el límite de las 20,000 visas por país, abolieron las cuotas separadas por hemisferio y finalmente establecieron un solo límite mundial que se redujo a 270,000 visas. Mientras que en 1965 los mexicanos que aspiraban a convertirse en inmigrantes legales no se enfrentaban con un límite numérico, para 1980 se encontraron compitiendo con aspirantes a inmigrantes de todo el mundo por una cifra limitada de visas.

Junto al final del Programa Bracero, estos cambios legislativos redujeron dramáticamente las posibilidades de ingreso legal y prácticamente garantizaron el aumento en la migración indocumentada. Mientras que a fines de los cincuenta cada año entraron a Estados Unidos cerca de 480,000 mexicanos como braceros o inmigrantes legales, el flujo total de ingreso de mexicanos por los canales legales descendió a 62,000 por año entre 1965 y 1985, el 13\% de su nivel previo. La diferencia entre la demanda de visas por parte de los patrones y trabajadores y el escaso número de ellas que ofrecía el gobierno se componía cada vez más de migración indocumentada y las aprehensiones anuales en la frontera se elevaron de manera estable desde 55,000 en 1965 a 1.6 millones en 1985.

En esencia el cambio en la política de inmigración en Estados Unidos después de 1965 transformó a la migración de mexicanos de un programa de jure de trabajadores huéspedes basado en la circulación de braceros en un programa de facto de trabajadores basado en la circulación de migrantes indocumentados (Durand y Massey 2003). Hasta 1985 este flujo permaneció abrumadoramente circular, y estuvo compuesto primordialmente por jóvenes que se trasladaban de ida y vuelta atraídos por el trabajo de temporada en la agricultura, la construcción, la manufactura y los servicios (Massey, Durand, Malone 2002). Bajo el programa de trabajadores temporales no oficial, que prevaleció entre 1965 y 1985, los mexicanos permanecieron como trabajadores desechables y como ciudadanos no deseados, como en el Programa Bracero, pero los flujos de mano de obra estuvieron regula- 
dos informalmente como producto de la vigilancia fronteriza en vez de que lo fueran bajo los términos de un acuerdo binacional formal.

Aunque la presencia de mexicanos indocumentados en Estados Unidos era técnicamente ilegal, hasta mediados de los años ochenta las consecuencias de esta ilegalidad eran relativamente benignas. El tamaño y el presupuesto de la patrulla fronteriza creció de forma modesta cada año para conservar el ritmo gradual de crecimiento del volumen subyacente de migración indocumentada y la probabilidad de aprehender a alguien que cruzara la frontera como indocumentado permaneció constante en cerca de 33\% (Massey y Singer 1995). La economía política de la migración mexicana antes de 1985 era tal que un migrante indocumentado podría esperar con cierto margen de sensatez que llegaría a la frontera y lograría entrar tras unos cuantos intentos con un riesgo personal reducido y con una inversión financiera modesta.

El aumento en la migración indocumentada después de 1965 se vio acompañado, empero, de una nueva satanización de los mexicanos. Los migrantes mexicanos fueron enmarcados cada vez más como una amenaza a la seguridad de la nación, a los trabajadores, a la cultura, a la forma de vida. Chavez (2001) estudió las portadas de las revistas estadounidenses dedicadas a la inmigración entre 1965 y 2000 y las clasificó como afirmativas, alarmistas o neutrales en su representación de los inmigrantes. Las portadas clasificadas como "afirmativas" utilizaban textos e imágenes para celebrar la inmigración; las portadas "alarmistas" utilizaban texto e imágenes para manifestar problemas, temores o peligros asociados con la inmigración; y las portadas "neutrales" eran acompañadas por artículos que ofrecían una cobertura equilibrada y factual de los temas de la inmigración que no era ni afirmativa ni alarmista.

Chávez encontró que los temas alarmistas predominaban de manera abrumadora en la cobertura de la inmigración después de 1965, caracterizando a dos tercios de todas las portadas dedicadas al tópico desde 1965 a 1999, en comparación con tan sólo el 9\% clasificado como neutral y 19\% afirmativo. La frecuencia de las portadas alarmistas también se incrementó notablemente con el tiempo. Mientras que el 18\% de las portadas alarmistas apareció en los años setenta, el $38 \%$ fue publicado en los años ochenta y el $45 \%$ en la década de los noventa. Los incrementos en los textos y las imágenes alarmistas coincidieron también con periodos de recesión en Estados Unidos (Chávez 2001:21-24).

Las palabras impresas en los textos que acompañaban a las imágenes por lo general reforzaban el sentido de alarma y urgencia comunicados por las imágenes (Chávez 2001). En un estilo que se ha conservado a lo largo del tiempo, los editores utilizaban notablemente las metáforas marinas, representando a la inmigración como una "ola gigante" que estaba "anegando" Estados Unidos y amenazaba con "inundar" su cultura. Durante los años setenta y ochenta, empero, apareció con mayor frecuencia una nueva metáfora a medida que los inmigrantes y la inmigra- 
ción fueron enmarcados cada vez más en términos marciales. La frontera MéxicoEstados Unidos era representada como un "campo de batalla" que estaba "siendo atacado" por parte de "invasores extranjeros" que constituían una "bomba de tiempo" que esperaba explotar y destruir la cultura y los valores estadounidenses. En esta representación militarizada, los oficiales de la patrulla fronteriza se convertían en "defensores" que estaban "en desventaja de armas" en sus intentos por "conservar la línea" en contra de las "hordas" (Dunn 1996; Andreas 2000).

Fuera marcial o marino el lenguaje utilizado, empero, siempre representaba a la inmigración proveniente de México como una "crisis". Retrocediendo a los primeros días de la república, los políticos han encontrado conveniente el satanizar a los inmigrantes durante los periodos de inquietud social e inseguridad económica (Higham 1955) y durante los años ochenta la representación simbólica de los inmigrantes como amenaza alcanzó nuevas cotas (Zolberg 2006). En particular Ronald Reagan, enmarcó a la inmigración como una cuestión de "seguridad nacional" ligada con sus acusaciones constantes de la Guerra Fría. Como consecuencia de las insurgencias comunista en centroamérica, predijo una "ola gigante de refugiados -y esta vez serán 'personas de a pie' y no personas en botes- llegando multitudinariamente a nuestro país en busca de un refugio frente a la represión comunista en el sur" (Washington Post, 21 de junio de 1983). En un discurso de 1986, recordó a los estadounidenses que los "terroristas y subversivos están a tan sólo dos días de manejo por carretera de [el cruce fronterizo de] Harlingen, Texas (citado en Kamen 1990) y su comisión de 1987 sobre el terrorismo reportó que los inmigrantes constituían una potencial quinta columna en Estados Unidos porque los extremistas se "alimentarían de la ira y la frustración de los inmigrantes centro y sudamericanos recientes que no realizarán su propia versión del sueño americano" (citado en Dunn 1996).

Esta denominación de la inmigración como una amenaza a la seguridad nacional, la representación simbólica de la frontera entre México y Estados Unidos como una fortaleza defensiva y la satanización de los latinos como subversivos alcanzó un crescendo a mediados de los años ochenta (Massey, Durand y Malone 2002). El año de 1986 fue crucial. A fines de ese año el congreso aprobó el decreto de reforma y control de la inmigración (Immigration Reform and Control Act-IRCA), que contenía tres medidas de largo alcance que drásticamente reconfiguraron la economía política de la migración y transformaron la posición de los mexicanos en Estados Unidos (Durand, Massey y Parrado 1999). En primer lugar, el IRCA incrementó notablemente el financiamiento para la vigilancia de la frontera, iniciando una expansión sin precedentes en la patrulla fronteriza que continuó sin interrupción durante dos décadas. En segundo lugar, autorizó dos programas de legalización: uno para los residentes a largo plazo que habían estado en el país por al menos cinco años y otro para trabajadores agrícolas en el corto plazo. Finalmente, crimi- 
nalizó el contratar trabajadores indocumentados y aplicó sanciones en contra de los empleados que lo hicieran a sabiendas.

\section{LA ESTRATIFICACIÓN RACIAL EN LA PRÁCTICA ACTUAL}

Después de 1986 el tamaño y el presupuesto de la patrulla fronteriza creció rápidamente, a un ritmo que ya no estaba conectado con el volumen subyacente de la migración (Durand, Massey y Malone 2002). A pesar de los enormes gastos en vigilancia fronteriza, sin embargo, la tasa de ingresos ilegales permaneció estable (Donato, Durand y Massey 1992). Para 1990 estaba claro que la legislación no estaba funcionando y que la migración crecía otra vez, por lo que el congreso aprobó una nueva serie de cambios restrictivos al decreto de inmigración y naturalización, imponiendo nuevos límites a la migración familiar legal, autorizando financiamiento para miles de oficiales adicionales en la patrulla fronteriza, haciendo más estrictas las sanciones contra los patrones, agilizando los procedimientos de deportación, incrementando las penas para las violaciones en la inmigración y reforzando la vigilancia interna. De una cifra de apenas 11,000 en 1985, la cifra anual de mexicanos arrestados en el interior de Estados Unidos y deportados a la fuerza creció de forma estable hasta alcanzar los 150,000 en 2005, la mayor cifra desde las campañas de deportación de la Gran Depresión.

La militarización de la frontera y la escalada de vigilancia en el interior ayudaron a romper el patrón tradicional de migración circular que había prevalecido a lo largo de la historia (Massey, Durand y Malone 2002). Mientras que la probabilidad de que un mexicano iniciara la migración indocumentada permaneció constante en los años después de aprobado el IRCA, la probabilidad de regresar a México una vez que se había logrado ingresar a Estados Unidos, se desplomó después de 1986. En vez de considerar como primera opción la de no ir a Estados Unidos, los migrantes indocumentados escogían en cambio permanecer más tiempo una vez que habían convertido en un éxito el azaroso cruce de la frontera para internarse en el país (Durand y Massey 2003).

La tasa decreciente de emigración y la tasa estable de inmigración se combinaron para incrementar la tasa de la migración neta indocumentada y causar una aceleración sin precedentes en la cifra de mexicanos que vivían al norte de la frontera. En esencia, las políticas de inmigración y de vigilancia fronteriza lograron lo contrario de lo que pretendían. En vez de reducir el flujo neto de ingreso anual de migrantes mexicanos, la redoblaron. Las políticas de inmigración y fronteriza de Estados Unidos transformaron la inmigración mexicana de ser un flujo circular de trabajadores varones en una población establecida de familias. Para el año 2008, la cifra total de mexicanos indocumentados que se encontraban al norte 
de la frontera había alcanzado los 7 millones y el número total de mexicanos nacidos fuera de Estados Unidos había ascendido a cerca de 12 millones.

Estas cifras denotan que una de cada diez personas nacidas en México vive ahora en Estados Unidos y cerca del 55\% tienen status ilegal. Al mismo tiempo, los inmigrantes han llegado a formar una creciente fracción de todos los mexicoamericanos, aproximadamente el 40\% en 2005; y la enorme cifra de indocumentados entre ellos significa que a mediados del siglo Xxi más de la mitad de todas las personas provenientes de México -y más de una quinta parte de todas las personas de origen mexicano- carecen de derechos sociales, políticos o económicos en Estados Unidos. Los mexicanos son ahora más explotables que en cualquier otra época desde la década de 1850.

En vez de culpar por el deterioro de los salarios y las condiciones de trabajo a los cambios estructurales en la economía política, sin embargo, los economistas conservadores como George Borjas (1995) han atribuido la tendencia a un "declive en la calidad de los inmigrantes", resaltando a los mexicanos de forma que sería conocida a los miembros de la comisión Dillingham. Aunque la satanización de los inmigrantes latinos como "invasores" y "terroristas" se redujo un poco durante el auge económico de los años noventa, estos marcos regresaron con más fuerza después del 11 de septiembre de 2001, tanto desde dentro como desde fuera de la academia.

Dentro de la academia, intelectuales como el especialista en ciencias políticas Samuel P. Huntington (2004) ofrecieron una nueva puesta en escena de las afirmaciones de la comisión Dillingham acerca de la incapacidad de asimilación de los inmigrantes latinoamericanos:

El persistente flujo de llegada de los inmigrantes hispanos amenaza con dividir a Estados Unidos en dos pueblos, dos culturas y dos lenguajes. A diferencia de los grupos de inmigrantes del pasado, los mexicanos y otros latinos no se han asimilado en la cultura dominante de Estados Unidos, formando en cambio sus propios enclaves lingüísticos y políticos desde Los Ángeles a Miami -y rechazando los valores angloprotestantes que construyeron el sueño americano. Estados Unidos ignora este desafío arriesgándose a sí mismo.

Fuera de la torre de marfil, quien antes escribiera los discursos de Nixon e intelectual conservador Patrick Buchanan (2006), ha advertido sobre un "complot azteca" fomentado por conspiradores mexicanos para reconquistar las tierras perdidas bajo el Tratado de Guadalupe-Hidalgo, haciendo efectiva de ese modo la "reconquista" del suroeste americano. Comparando a los mexicanos con los bárbaros que invadieran la Roma antigua, se refiere a "la invasión y conquista del tercer mundo a Estados Unidos" como un "estado de emergencia". En una entrevista con la revista Time, advirtió: 
Si no logramos el control de nuestras fronteras y paramos la mayor invasión de la historia, veo la disolución de Estados Unidos y la pérdida del suroeste americano -cultural y ligüísticamente, si es que no políticamente- frente a México. Podría convertirse en parte de México de la misma forma en que Kosovo es ahora parte de Albania (28 de agosto de 2006, p. 6).

Aun más hipérboles vendrían de parte de Chris Simcox del Minutemen Civil Defense Corps, un grupo "vigilante" fundado para patrullar la frontera MéxicoEstados Unidos. En la página de Internet de la organización, plantea retóricamente la pregunta: "iexplotan los terroristas nuestras porosas fronteras?" y luego aporta la siguiente respuesta: "sabemos que los narcotraficantes, los pandilleros y demasiados extranjeros inquietan a nuestras comunidades y amenazan nuestra seguridad pública".

Los fundamentos legales para la criminalización no sólo de los contratos a indocumentados, sino de los propios migrantes indocumentados se establecieron en el decreto de 1996 contra el terrorismo, titulado Antiterrorism and Effective Death Penalty Act, que dio al gobierno federal nuevos poderes policíacos para la "exclusión expedita" de cualquier extranjero que hubiera alguna vez cruzado la frontera sin documentos ( $\sin$ importar su actual status legal actual) o que hubiera alguna vez cometido algún delito menor (sin importar cuánto tiempo atrás). Estas medidas -que llegan tras una década de leyes antidrogas draconianas y de una legislación que señala un máximo de tres faltas a la ley- hicieron que en un instante miles de residentes legales se convirtieran en extranjeros susceptibles de ser deportados, muchos de los cuales entraron a Estados Unidos como infantes y pasaron todas sus vidas en Estados Unidos.

La ley delegó también en el departamento de estado la autoridad absoluta para designar a cualquier organización como "terrorista", haciendo con ello que todos los miembros de grupos así denominados fueran inmediatamente susceptibles de exclusión y deportación. También redujo las razones para el asilo y añadió el contrabando de extranjeros en busca de asilo a la lista de crímenes cubiertos por el estatuto RICO (organizaciones corruptas influidas por la extorsiónRacketeer Influenced Corrupt Organizations), al tiempo que limitaba seriamente las posibilidades de apelación judicial de las deportaciones. Según Legomsky (2000: 1616), esta legislación constituye "el más virulento ataque a la revisión judicial de las decisiones en inmigración" lanzada jamás "al crear nuevas cortes de remoción que permiten el uso de procedimientos secretos para retirar a extranjeros sospechosos de terrorismo; al trasladar la autoridad para hacer 'remociones expeditas' a los inspectores de inmigración en los puertos de entrada; y al establecer límites sin precedente en la revisión judicial de las decisiones de inmigración".

Los eventos del 11 de septiembre ocurrieron pues en el contexto de una creciente animadversión en contra de los inmigrantes y un ataque creciente a sus libertades civiles y derechos sociales. En respuesta a los ataques terroristas, el 26 
de octubre de 2001 el congreso aprobó el decreto Patriota USA, que concedía a la rama ejecutiva nuevos poderes ampliados para deportar, sin audiencia o presentación de evidencia a todos los extranjeros -legales e ilegales- acerca de los cuales el Fiscal General tuviera "razón para creer" que podrían cometer, apoyar o facilitar actos de terrorismo. Por primera vez desde el decreto de extranjeros y sedición (Alien and Sedition Act) de 1798, el congreso votó para permitir el arresto, encarcelamiento y deportación de no ciudadanos con una orden del Fiscal General sin una revisión judicial.

A lo largo de la historia de Estados Unidos los ataques a los inmigrantes han aumentado y disminuido. Lo que distingue a la actual ola de histeria en contra de los inmigrantes respecto a sus predecesoras no es su satanización de los extranjeros ni el duro tratamiento a los no ciudadanos como tales, sino su uso del temor a los extranjeros para lanzar un ataque más amplio a las libertades civiles, tanto de los inmigrantes como de todos los estadounidenses, ya que el decreto PATRIOTA permite además la vigilancia y encarcelamiento sin precedentes de ciudadanos estadounidenses, nuevamente a discreción de la rama ejecutiva y sin revisión. Como hace notar Zolberg (2006): "mientras que los retos planteados por la migración internacional son reales y requieren de reconsideración mundial de los regímenes existentes, el resurgimiento de las respuestas nativistas constituye una amenaza más inmediata a la democracia liberal que la inmigración misma. No es coincidencia que el único ciudadano estadounidense que ha sido retenido en detención indefinida sin levantarle cargos y sin una audiencia sea un latino de piel oscura, José Padilla.

\section{LAS CONSECUENCIAS DE LA RACIALIZACIÓN}

Todo el trabajo de trazado de límites realizado por los académicos, ideólogos y políticos para enmarcar a los inmigrantes como una amenaza y clasificarlos como socialmente indeseables ha afectado a la opinión pública, volviéndola constantemente en contra de los latinos. Según las encuestas realizadas por los Pew Charitable Trusts, todavía en 2000 sólo el 38\% de los estadounidenses estaba de acuerdo con que "los inmigrantes en la actualidad son una carga para nuestro país porque toman nuestros empleos, viviendas y atención médica". Cinco años más tarde, el porcentaje se había incrementado al 44\%; y cuando el ataque de la retórica en contra de los inmigrantes había alcanzado un crescendo en 2006, éste se convirtió en el punto de vista de una mayoría situada en el 52\%. A tono con este cambio, el porcentaje de estadounidenses que consideraron a ls inmigración como un problema nacional moderadamente grande o muy grande se elevó de 69\% en 2002 a 74\% en 2006 (Kohut y Suro 2006).

Para el año 2006, casi la mitad de todos los estadounidenses (48\%) opinaba que los "recién llegados de otros países amenazan los valores y costumbres esta- 
dounidenses tradicionales" y 54\% dijo que Estados Unidos necesitaba ser "protegido en contra de la influencia extranjera". No es de sorprender que, dadas estas visiones, el 49\% dijera que creían que los "inmigrantes se reservan entre ellos y no tratan de ajustarse aquî"; el 56\% dijo que ellos "no pagan los impuestos que les corresponden"; el 58\% creía que los inmigrantes "no aprenden inglés en un periodo de tiempo razonable"; y el $60 \%$ de quienes habían escuchado sobre los "Minutemen" aprobaban sus actividades (Kohut y Suro 2006).

Los estudios recientes de Lee y Fiske (2006) aplicaron el modelo del contenido de estereotipos a diversos grupos de inmigrantes. Con base en las clasificaciones de los encuestados y de otros sujetos, trazaron la posición de diferentes grupos en el espacio bidimensional definido por la intersección de calidez y competencia; los resultados de este ejercicio se reproducen en la figura 2. Como se esperaba, el espacio social ocupado por lo general por los miembros del propio grupo, a los que se estima (alta calidez, alta competencia) incluye a grupos como los canadienses, europeos, inmigrantes con documentos e inmigrantes de la tercera generación. De manera similar, el espacio ocupado por lo general por los grupos externos a los que se envidia (alta competencia, baja calidez) lo ocupan usualmente las clásicas minorías del hombre medio como los coreanos, chinos, japoneses y asiáticos. Los europeos del este, la primera generación de inmigrantes, los rusos, alemanes, franceses y los inmigrantes del centro-este europeo ocupan una posición intermedia de calidez moderada y competencia moderada.

\section{FIGURA 2}

El modelo de contenido de los estereotipos aplicado a los inmigrantes

(Fuente: Lee y Fiske 2006)

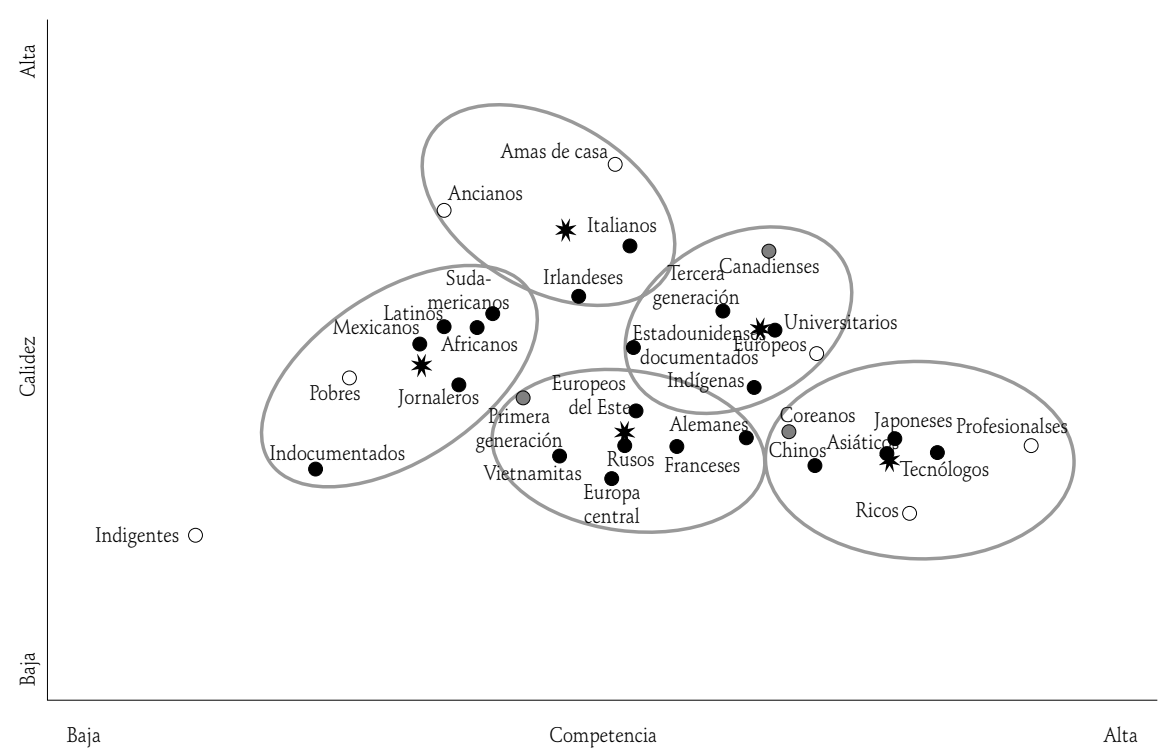


Nótese, sin embargo, qué grupos ocupan el espacio de baja calidez y baja competencia que corresponde a los grupos externos más despreciados: sudamericanos, latinos, mexicanos, jornaleros y africanos; y el grupo más despreciado de todos los inmigrantes es el de los migrantes indocumentados, quienes obtienen el más bajo puntaje de todos en calidez y competencia, de modo que se aproximan a la porción de la gráfica usualmente reservada sólo para los grupos más detestados y socialmente estigmatizados, como los criminales y narcotraficantes. En términos sociales, se trata de un territorio peligroso, ya que implica que los migrantes indocumentados no son percibidos como plenamente humanos en el nivel neural más fundamental de la cognición, abriéndose así una puerta al tratamiento más duro, explotador y cruel que los seres humanos son capaces de infligir a otros humanos.

En este contexto, el sistema de inmigración de Estados Unidos ha asumido una nueva posición central en la explotación y exclusión de los latinos. La puesta en práctica de las sanciones en contra de los patrones incrementó la discriminación de los hispanos en los mercados de trabajo estadounidenses, bajando sus salarios, deprimiendo los retornos de capital humano y cerrando trayectorias largamente establecidas de movilidad ascendente. Al mismo tiempo, el IRCA promovió un cambio masivo a la subcontratación en el mercado de mano de obra no calificada. La militarización de la frontera entre México y Estados Unidos, mientras tanto, aumentó la tasa de crecimiento de la población inmigrantes no documentada para incrementar la cifra de las personas en las categorías vulnerables y susceptibles de ser explotadas. Finalmente, a medida que aumentó la discriminación privada y mayores porciones de la población fueron explotadas económicamente, el congreso incrementó los castigos sociales por ser pobre, hispano, extranjero e indocumentado, alejando incluso a los inmigrantes legales de los servicios públicos para los cuales hasta ese momento tenían derechos vigentes.

Como resultado de estas acciones deliberadas de política, la economía política que enfrentan los hispanos es ahora más dura y más punitiva que la prevaleciente antes de 1986. Históricamente, los hispanos han ocupado una posición intermedia entre los negros y los blancos en el sistema de estratificación estadounidense, pero con la reestructuración de la economía política de la inmigración a fines de los años ochenta y principios de los noventa, la posición relativa de los hispanos decayó y vinieron a reemplazar a los afroamericanos en el fondo de la jerarquía de clases. La figura 3 ilustra este cambio al mostrar la razón del ingreso de las minorías frente a los blanco e hispanos entre 1972 y 2002.

Las líneas más bajas muestran las razones de los ingresos de los hombres hispanos y negros. A principios de los años setenta, el hombre negro promedio ganaba aproximadamente el $60 \%$ de lo que ganaba el hombre blanco promedio, mientras que los hombres hispanos ganaban alrededor del 70\% del nivel del hombre blanco. Estas razones relativas de ingreso prevalecieron los primeros años de los ochenta, pero a la mitad de la década el IRCA transformó la estructura del mer- 
cado de mano de obra de bajos ingresos y se deterioró la posición de negociación de los hombres hispanos. De 1983 a 1986, la razón de ingresos entre los hispanos frente a los blancos cayó de .70 a cerca de .60, en donde se mantuvo hasta 1991, y luego se desplomó por debajo de .60 por primera vez en la historia. En esa época los ingresos de los hombres negros comenzaron a subir en relación con los ingresos de los hombres blancos y en 1993 la razón del ingreso se cruzó con la línea de la razón de hispanos-blancos y desde ese momento los hispanos reemplazaron a los negros en la parte baja de la jerarquía de los ingresos masculinos.

\section{FIGURA 3}

Ingreso personal de hispanos y negros como razón del ingreso de los blancos

(Fuente: Oficina del censo de EUA)

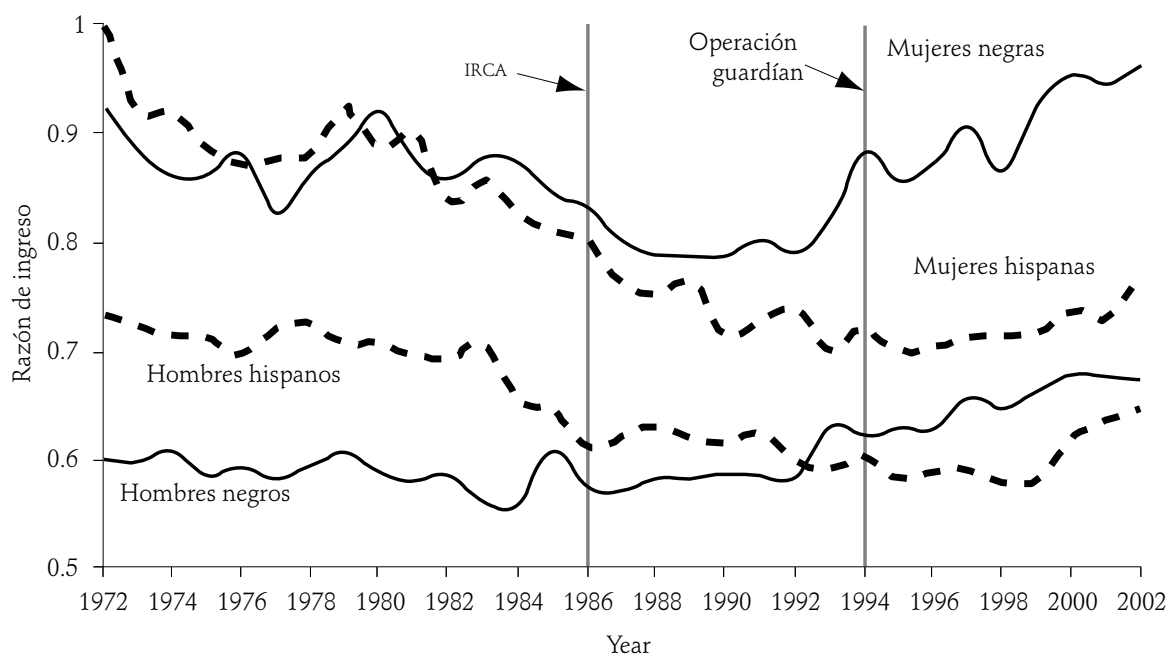

Las dos líneas superiores muestran las tendencias en las ganancias relativas de las mujeres hispanas y negras para revelar un intercambio similar de posiciones, ocurrida aun más temprano que la acontecida entre los hombres de las minorías. En 1972 las mujeres hispanas recibían el mismo ingreso que las mujeres blancas, mientras que las mujeres negras ganaban cerca del $92 \%$ de sus contrapartes blancas. Durante los años setenta y ochenta, empero, las ganancias de las mujeres en los dos grupos minoritarios se deterioraron en relación con aquellos de las mujeres blancas; pero la caída fue más rápida entre las mujeres hispanas y en 1981 las dos líneas se cruzaron y desde entonces las mujeres hispanas reemplazaron a las mujeres negras en el fondo de la jerarquía de las ganancias femeninas.

A pesar de este cruce temprano, sin embargo, las razones entre los ingresos de hispanos-blancos y negros-blancos permanecieron bastante cercanas entre sí hasta que se aprobó el IRCA en 1986. A partir de esta fecha, el deterioro en el ingreso femenino negro se hizo más lento y luego, a principios de los noventa, se revirtió y comenzó a subir. En contraste, el deterioro de las ganancias de las mujeres his- 
panas se aceleró y las dos razones de ingreso comenzaron a separarse a pasos acelerados, dejando un creciente hiato. De 1987 a 2002, la razón del ingreso entre las mujeres negras frente a las mujeres blancas se incrementó de .80 a .96, mientras que la razón del ingreso de las mujeres hispanas descendió de .80 a cerca de .70, subiendo nuevamente al final de la década a cerca de .77.

Las cambiantes fortunas de los hispanos y afroamericanos en el mercado de fuerza de trabajo en Estados Unidos se refleja claramente también en las estadísticas sobre la pobreza en Estados Unidos, como se muestra en la figura 4. Históricamente, las tasas de pobreza hispana estaban mucho más abajo que las correspondientes a los negros, pero a lo largo de las décadas de 1980 y 1990 desapareció el diferencial y los dos grupos terminaron el siglo xx casi en la misma paridad en términos de privación material. La figura 4 muestra la razón de la pobreza hispana frente a la pobreza negra de 1972 a 2002. Durante los años setenta y principios de los ochenta, las tasas de pobreza hispana fluctuaron en cerca de 70\% a 80\% del nivel de los negros, pero durante fines de los ochenta y principios de los noventa las tasas de pobreza hispana aumentaron y llegaron al rango entre el 80 y el $90 \%$ de las tasas negras. Con el incremento en el establecimiento por parte de los migrantes indocumentados y el cambio a la migración familiar tras el reforzamiento de la frontera comenzado en la operación bloqueo en El Paso, las tasas de pobreza de los hispanos llegaron a equipararse o exceder las de los negros y la razón subió por encima de 1.0 por primera vez desde que se recolectan estadísticas de pobreza.

\section{FIGURA 4}

Razón entre las tasas de pobreza de los hispanos frente a los negros (Fuente: Oficina del censo de EUA)

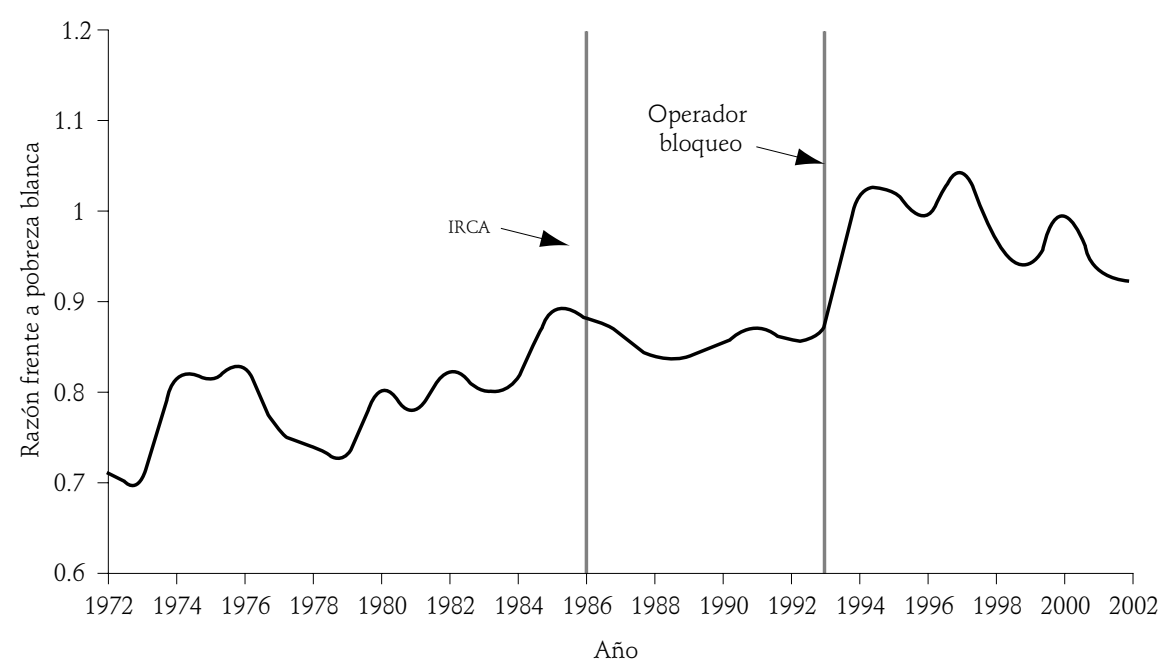

El deterioro en la posición de los hispanos en el mercado de trabajo en relación con la que ocupan los negros ha estado acompañado por un cambio paralelo en 
los mercados de vivienda, ya que el estudio de discriminación en la vivienda de 2000 (Housing Discrimination Study) reveló un incremento significativo en la discriminación contra los hispanos. Mientras que en 1989 los hispanos tenían una probabilidad de $19 \%$ menor que los negros de experimentar un tratamiento adverso en los mercados de renta de vivienda estadounidenses, en 2000 tenían una probabilidad 8\% mayor de sufrir discriminación. Además, aunque la incidencia de tratamiento discriminatorio decayó para ambos grupos en el mercado de ventas, la caída para los hispanos fue mucho más pequeña. Como resultado, mientras que los blancos en 1989 tenían el doble de probabilidades de experimentar discriminación en las ventas de vivienda, para el 2000 los hispanos tenían un 18\% más de probabilidad de ser discriminados (Turner et al., 2002). En su revision de las viviendas en renta en el área de la Bahía de San Francisco, Purnell, Isardi y Baugh (1999) documentaron hallazgos consistentes con los datos anteriores, al señalar un extenso "perfilamiento lingüístico" que excluía a los hablantes de la variante chicana del inglés así como a los que hablaban inglés negro del acceso a la vivienda.

A medida que aumentó la discriminación en contra de los latinos en los mercados de vivienda, también se incrementaron los niveles de segregación residencial de los hispanos. Mientras que el nivel general de segregación de los negros descendió en 10 puntos en la década pasada y el aislamiento en los barrios negros cayó en 12 puntos, la segregación hispana aumentó en 6 puntos y el aislamiento aumentó en 10 puntos (Charles 2003); y mientras que los hispanos no satisficieron los criterios para la hipersegregación en ninguna de las áreas metropolitanas durante los años ochenta o noventa, para el 2000 tanto Nueva York como Los Ángeles habían ganado la dudosa distinción de convertirse en ciudades hipersegregadas para los residentes latinos (Wilkes y Iceland 2004).

En el ámbito social, los investigadores también han documentado el "escalofriante efecto" de la legislación de inmigración y bienestar en el uso de los servicios públicos por parte de los inmigrantes (Fix y Zimmerman 2004). Entre los migrantes indocumentados, el uso de los servicios sociales, siempre bastante bajo, cayó todavía más, de modo que después de 1996 menos del 5\% reportó recibir estampillas canjeables por comida, beneficios sociales o seguros de desempleo mientras estuvo en Estados Unidos y sólo el 7\% reportó inscribir a sus hijos en escuelas públicas. Es aun más sorprendente el declive en los servicios utilizados por los inmigrantes legales. Después de 1996, las tasas de utilización de beneficios sociales, seguro de desempleo y estampas de comida cayeron todas notablemente a 10\% o menos (Donato, Massey y Wagner 2006) y, según cálculos de Borjas (2004), cada 10\% de reducción en la fracción de la población que sobrevive con asistencia pública, aumenta el número relativo de hogares con inseguridad alimenticia en cinco puntos porcentuales.

Parece por tanto que el congreso lanzó una clara señal en 1996 a los inmigrantes legales e ilegales en el sentido de que no eran bienvenidos en lo que quedaba del estado de bienestar estadounidense y ambos conjuntos de inmigrantes reci- 
bieron el mensaje de manera clara y en volumen alto. Además de restringir la elegibilidad de los inmigrantes legales para recibir beneficios de medios federales comprobables, sin embargo, el congreso en 1996 aumentó también el nivel de ingresos requerido para obtener una garantía de sostenimiento. Este documento se requiere para todas las personas que buscan patrocinar el ingreso legal de un miembro de la familia y requiere que en el hogar se compruebe que tiene recursos suficientes para sostener al inmigrante en caso de que éste llegara a la indigencia. El congreso, por supuesto, buscaba limitar la inmigración familiar, pero en vez de quedarse inmóviles y permitir que el gobierno los declarara no aptos para traer a sus familiares, los hogares de inmigrantes se opusieron a la medida enviando a más miembros de la familia al mercado de fuerza de trabajo para aumentar las ganancias colectivas de modo que pudieran alcanzar el nivel de ingresos más alto. Después de 1996, los hijos de más edad en las familias mexicanas desertaron más de las escuelas y fueron a trabajar, deprimiendo aun más los bajos niveles de escolaridad entre los niños latinos y minando de manera permanente sus prospectos económicos (Donato, Massey y Wagner 2006).

Aunque los hispanos parecen no haber sido arrastrados hacia el complejo industrial carcelario al mismo grado que los afroamericanos, no obstante comprenden un segmento importante de los recluidos que es desproporcionado en relación con su proporción en la población. Cerca del $5 \%$ de los hombres hispanos entre 20 y 40 años de edad estaban en prisión o en la cárcel en el años 2000, en comparación con el 12\% de los negros y el $2 \%$ de los blancos (Western 2006). Además, en la primavera de 2006 la Casa de Representantes aprobó una legislación (HR4437) patrocinada por el representante republicano James Sensenbrenner para hacer que la "presencia ilegal" en Estados Unidos se convirtiera en un delito (felony). Definía la presencia ilegal tan ampliamente que casi cualquier violación de la inmigración, sin importar cuán menuda, técnica o intencional, se convertía en un crimen federal que hacía a quien lo cometiera susceptible de encarcelamiento y deportación. Si este decreto pasa el Senado para convertirse en ley, hará que 21 millones de personas sean instantáneamente sujetas de encarcelamiento y representará la más grande expansión del complejo industrial carcelario de la historia, triplicando potencialmente el tamaño de la población carcelaria en Estados Unidos, que ya es la de mayor tamaño en el planeta.

\section{CONCLUSIÓN}

En su obra American Apartheid, Massey y Denton (1993) ofrecen un cartabón de cómo construir una clase inferior:

Para comenzar, selecciónese un grupo minoritario cuyos miembros de algún modo se puedan identificar como diferentes de la mayoría. Una vez que se ha seleccionado el grupo el siguiente paso para crear una clase inferior es confinar a sus miembros en un 
pequeño número de áreas de residencia continuas... Una vez que se ha asegurado la segregación de un grupo en la sociedad, el siguiente paso para crear una clase inferior es aumentar su tasa de pobreza...La interacción entre pobreza y segregación actúa para concentrar una diversidad de características sociales y económicas perniciosas. A través de una prolongada exposición a la vida en un barrio racialmente aislado e intensivamente pobre, la pobreza muy probablemente se pase a la siguiente generación. Cuando se alcance este punto, se habrá creado una estructura eficiente y de funcionamiento correcto para la construcción y mantenimiento de una clase urbana inferior.

La evidencia revisada aquí sugiere que las políticas de Estados Unidos están trasladando a los mexicanos de manera constante hacia una posición lejana de su posición intermedia en la jerarquía económica y hacia la formación de una clase inferior. Los niveles de segregación aumentan, la discriminación se incrementa, la pobreza se profundiza, los niveles de escolaridad se estancan y la red de seguridad social se ha interrumpido de manera deliberada para permitir que los inmigrantes caigan a través de ella. El que los mexicanos se conviertan en una nueva clase inferior está todavía por verse; pero lo que sí es claro es que tras ocupar una posición intermedia entre los blancos y los negros durante generaciones, las fortunas económicas de los mexicanos ahora han descendido a niveles iguales o inferiores a los que ocupan los afroamericanos. De manera crítica, además, los mexicanos están mucho peor que los estadounidenses negros. Cualesquiera barreras discriminatorias que los afroamericanos todavía enfrenten, al menos tienen el derecho legal a vivir y trabajar en Estados Unidos. En contraste, una quinta parte de todos los mexicoamericanos carece de la posibilidad de realizar exigencias legales en la sociedad estadounidense por estar presentes sin autorización y esta fracción aumenta rápidamente. Si la proporción de latinos con status indocumentado continua subiendo, la clase inferior resultante estará incluso "mejor" que la que surgió en las ciudades negras centrales durante los años ochenta. Sus miembros no solo serán explotados y excluidos; estarán fuera de la misma ley, serán susceptibles de deportación inmediata y quizá incluso en serio riesgo de ser encarcelados por el crimen menor de vivir y trabajar en Estados Unidos sin permiso.

\section{BIBLIOGRAFÍA}

Alba, Richard D. 1990. Ethnic Identity: The Transformation of White America. Nueva Haven: Yale University Press.

ANDREAS, Peter. 2000. Border Games: Policing the US-Mexico Divide. Ithaca: Cornell University Press.

BArgh, John A. 1996. "Automaticity in Social Psychology." Pp. 169-83 en E. Tory Higgins y Arie W. Kruglanski, eds., Social Psychology: Handbook of Basic Principles. Nueva York: Guilford 
BARTH, Fredrik. 1969. Ethnic Groups and Boundaries: The Social Organization of Culture Difference. Boston: Little, Brown.

1981. Process and Form in Social Life. London: Routledge and Kegan Paul.

BeAn, Frank D. y Marta Tienda. 1987. The Hispanic Population of the United States. Nueva York: Russell Sage Foundation.

Bodenhausen, Galen V. y M. Lichtenstein. 1987. "Social Stereotypes and Information

Processing Strategies: The Impact of Task Complexity." Journal of Personality and Social Psychology 52:871-80.

y Robert S. Wyer. 1985. "Effects of Stereotypes on Decision Making and Information Processing Strategies." Journal of Personality and Social Psychology 48:267-82.

BorJAS, George J. 1995. "Assimilation and Changes in Cohort Quality Revisited: What Happened to Immigrant Earnings in the 1980s?" Journal of Labor Economics 13:201245.

, 2004. "Food Insecurity and Public Assistance." Journal of Public Economics 88: 1421-43.

Buchanan, Patrick J. 2006. State of Emergency: The Third World Invasion and Conquest of America. Nueva York: Thomas Dunne Books.

CALAVITA, Kitty. 1992. Inside the State: The Bracero Program, Immigration, and the I.N.S. Nueva York: Routledge.

Cardoso, Lawrence A. 1980. Mexican Emigration to the United States, 1897-1931: SocioEconomic Patterns. Tucson: University of Arizona Press.

Charles, Camille Z. 2003. "The Dynamics of Racial Residential Segregation." Annual Review of Sociology 29: 67-207.

Chavez, Leo R. 2001. Covering Immigration: Population Images and the Politics of the Nation. Berkeley: University of California Press.

Damasio, Antonio R. 1999. The Feeling of What Happens: Body and Emotion in the Making of Consciousness. Nueva York: Harcourt Brace.

De Leon, Arnoldo. 1993. Mexican Americans in Texas: A Brief History. Wheeling, IL: Harlan Davidson.

Donato, Katharine M., Jorge Durand y Douglas S. Massey 1992. "Stemming the Tide? Assessing the Deterrent Effects of the Immigration Reform and Control Act." Demography 29:139-57.

, Douglas S. Massey y Brandon Wagner. 2006. "The Chilling Effect: Public Service Usage by Mexican Migrants to the United States." Trabajo presentado en la reunion annual de la Population Association of America, Los Ángeles.

Dunn, Timothy J. 1996. The Militarization of the U.S.-Mexico Border, 1978-1992: Low-Intensity Conflict Doctrine Comes Home. Austin: Center for Mexican American Studies, University of Texas at Austin.

Durand, Jorge y Patricia Arias. 2000. La Experiencia Migrante: Iconografía de la Migración México-Estados Unidos. México, DF: Altexto.

y Douglas S. Massey. 2003. "The Costs of Contradiction: U.S. Immigration Policy 1986-1996." Latino Studies 1:233-52.

, Douglas S. Massey y Emilio A. Parrado. 1999."The New Era of Mexican Migration to the United States." Journal of American History 86:518-36. 
FIske, Susan T. 1998. "Stereotyping, Prejudice y Discrimination." Pp. 357-414 in Daniel T. Gilbert, Susan T. Fiske y Gardner Lindzey, eds., The Handbook of Social Psychology, Volume I, Fourth Edition. Nueva York: McGraw Hill , 2003. Social Beings: A Core Motives Approach to Social Psychology. Nueva York: Wiley.

, Amy J.C. Cuddy, Peter Glick y Jun Xu. 2002. "A Model of (Often Mixed) Stereotype Content: Competence and Warmth Respectively Follow from Perceived Status and Competition." Journal of Personality and Social Psychology 82:878-902.

FIX, Michael y Wendy Zimmermann. 2004. "The Legacy of Welfare Reform for U.S. Immigrants." Pp. 337-53 en Douglas S. Massey y J. Edward Taylor, eds., International Migration: Prospects and Policies in a Global Market. Oxford: Oxford University Press.

GIERYN, Thomas F. 1983. "Boundary-work and the Demarcation of Science from Nonscience: Strains and Interests in Professional Ideologies of Scientists." American Sociological Review 48:781-795.

Grebler, Leo, Joan Moore y Ralph Guzman. 1970. The Mexican-American People: The Nation's Second Largest Minority. Nueva York: Free Press.

Gutierrez, David. 1995. Walls and Mirrors: Mexican Americans, Mexican Immigrants, and the Politics of Ethnicity. Berkeley: University of California Press.

Harris, Lasana T. y Susan T. Fiske. 2006. "Dehumanizing the Lowest of the Low: NeuroImaging Responses to Extreme Outgroups." Psychological Science 17(10): 847-53.

Higham, John. 1955. Strangers in the Land: Patterns of American Nativism, 1860-1925. New Brunswick, N.J., Rutgers University Press, 1955.

Hoffman, Abraham. 1974. Unwanted Mexican Americans in the Great Depression: Repatriation Pressures, 1929-1939. Tucson: University of Arizona Press.

Huntington, Samuel P. 2004. "The Hispanic Challenge." Foreign Policy, March/April, pp. 1-12. http://www.foreignpolicy.com/story/cms.php?story_id=2495

Iceland, John and Rima Wilkes. 2006. "Does Socioeconomic Status Matter? Race, Class, and Residential Segregation." Social Problems 53:248-73.

JACOBSon, Matthew F. 1999. Whiteness of a Different Color: European Immigrants and the Alchemy of Race. Cambridge, MA: Harvard University Press.

Jaffe, Abraham J., Ruth M. Cullen y Thomas D. Boswell.1980. The Changing Demography of Spanish Americans. Nueva York: Academic Press.

Kahneman, Daniel y Amos Tversky. 2000. Choices, Values, and Frames. Nueva York: Cambridge University Press.

Kamen, Al. 1990. "Central America is no Longer the Central Issue for Americans." Austin American Statesman, Octubre 21.

KoHut, Andrew y Roberto Suro. 2006. No Consensus on Immigration Quandary or Proposed Fixes. Washington, D.C.: Pew Research Center for the People and the Press and Pew Hispanic Center.

Konner, Melvin. 2002. The Tangled Wing: Biological Constraints on the Human Spirit. Nueva York: Henry Holt \& Co.

Lakoff, George. 2002. Moral Politics: How Liberals and Conservatives Think. Chicago: University of Chicago Press.

y Mark Johnson. 2002. Metaphors We Live By. Chicago: University of Chicago Press. 
Lamont, Michele y Vireg Molnar. 2002. "The Study of Boundaries in the Social Sciences." Annual Review of Sociology 28.167-95.

LeDoux, Joseph. 1996. The Emotional Brain: The Mysterious Underpinnings of Emotional Life. Nueva York: Simon and Schuster.

Lee, Tiane L. y Susan T. Fiske. 2006. "Not an Outgroup, Not Yet an Ingroup: Immigrants in the Stereotype Content Model." International Journal of Intercultural Relations 30: 751-68.

Legomsky, Stephen H. 2000. "Fear and Loathing in Congress and the Courts: Immigration and Judicial Review." Texas Law Review 78:1612-20.

Leslie, Lisa M., V.S. Constantine y Susan T. Fiske. 2006. "The Princeton Quartet: How Are Stereotypes Changing?" Trabajo inédito, Department of Psychology, Princeton University.

MacLachlan, Colin M. y William H. Beezley. 2003. El Gran Pueblo: A History of Greater Mexico, Third Edition. Nueva York: Prentice-Hall.

Massey, Douglas S. y Nancy A. Denton. 1993. American Apartheid: Segregation and the Making of the Underclass. Cambridge: Harvard University Press.

— Jorge Durand y Nolane J. Malone. 2002. Beyond Smoke and Mirrors: Mexican Immigration in an Era of Economic Integration. Nueva York: Russell Sage Foundation.

y Audrey Singer. 1995. "New Estimates of Undocumented Mexican Migration and the Probability of Apprehension." Demography 32:203-11.

Mazon, Mauricio. 1984. The Zoot-Suit Riots: The Psychology of Symbolic Annihilation. Austin: University of Texas Press.

Morales, Patricia. 1982. Indocumentados Mexicanos. México, DF: Editorial Grijalvo.

Obregon Pagan, Eduardo. 2006. Murder at the Sleepy Lagoon: Zoot Suits, Race, and Riot in Wartime L.A. Chapel Hill: University of North Carolina Press.

PanKSePp, Jaak. 1998. Affective Neuroscience: The Foundations of Human and Animal Emotions. Nueva York: Oxford University Press.

Perlmutter, Phillip. 1999. Legacy of Hate: A Short History of Ethnic, Religious, and Racial Prejudice in America. Nueva York: M.E. Sharp.

Purnell, Thomas, William Idsardi y John Baugh. 1999. "Perceptual and Phonetic Experiments on American English Dialect Identification." Journal of Language and Social Psychology 18:10-30.

ReISLER, Mark. 1976. By the Sweat of their Brow: Mexican Immigrant Labor in the United States 1900-1940. Westport, CN: Greenwood Press.

Sanchez, George I. 1995. Becoming Mexican American: Ethnicity, Culture, and Identity in Chicano Los Angeles, 1900-1945. Nueva York: Oxford University Press.

Stangor, Charles, L. Lynch, C. Duan y B. Glass. 1992. "Categorization of Individuals on the Basis of Multiple Social Features." Journal of Personality and Social Psychology 62: 207-18.

TAYLOR, Shelly E., Susan T. Fiske, Nancy L. Etcoff y Audrey J. Ruderman. 1978. "Categorical Bases of Person Memory and Stereotyping." Journal of Personality and Social Psycho$\log y$ 36: 778-93.

Tilly, Charles. 1998. Durable Inequality. Berkeley: University of California Press. 
Turner, Margery A., Stephen L. Ross, George C. Galster y John Yinger. 2002. Discrimination in Metropolitan Housing Markets: National Results from Phase I. Washington, D.C.: U.S. Department of Housing and Urban Development.

U.S. Commission on Immigration. 1911. Immigrants in Industries: Part 25: Japanese and Other Immigrant Races in the Pacific Coast and Rocky Mountain States: Agriculture. Washington, D.C., USA: Government Printing Office.

Western, Bruce. 2006. Punishment and Inequality in America. Nueva York: Russell Sage Foundation.

WiLKes, Rima and John Iceland. 2004. "Hypersegregation in the Twenty-First Century: An Update and Analysis." Demography 41:23-36.

Zajonc, Robert B. 1998. "Emotions." Pp. 591-634 in Daniel T. Gilbert, Susan T. Fiske y Gardner Lindzey, eds., The Handbook of Social Psychology. Boston: McGraw-Hill.

Zamora, Emilio. 1993. The World of the Mexican Worker in Texas. College Station: Texas A\&M Press.

Zolberg, Aristide R. 2006. A Nation by Design: Immigration Policy in the Fashioning of America. Nueva York: Russell Sage Foundation. 
